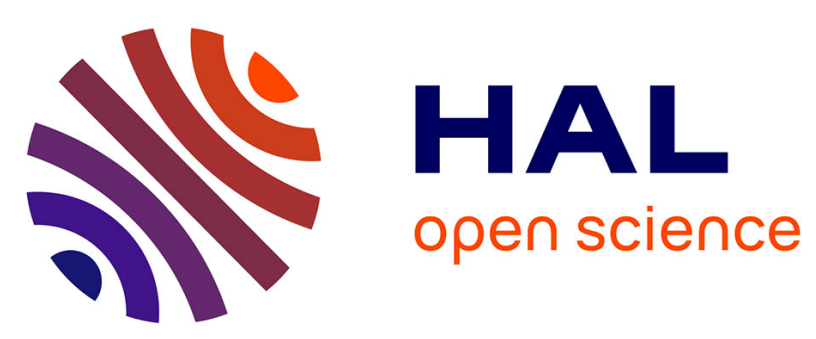

\title{
Potential Mechanisms Involved in Resistant Phenotype of MCF-7 Breast Carcinoma Cells to Ionizing Radiation-Induced Apoptosis
}

Yan-Lin Wang, Hong Zhang, Ning Li, Xiaohu Wang, Ji-Fang Hao, Wei-Ping Zhao

\section{To cite this version:}

Yan-Lin Wang, Hong Zhang, Ning Li, Xiaohu Wang, Ji-Fang Hao, et al.. Potential Mechanisms Involved in Resistant Phenotype of MCF-7 Breast Carcinoma Cells to Ionizing Radiation-Induced Apoptosis. The Seventh International Symposium on Swift Heavy Ions in Matter, Jun 2008, Lyon, France. hal-00201670

\section{HAL Id: hal-00201670 \\ https://hal.science/hal-00201670}

Submitted on 27 Jul 2008

HAL is a multi-disciplinary open access archive for the deposit and dissemination of scientific research documents, whether they are published or not. The documents may come from teaching and research institutions in France or abroad, or from public or private research centers.
L'archive ouverte pluridisciplinaire HAL, est destinée au dépôt et à la diffusion de documents scientifiques de niveau recherche, publiés ou non, émanant des établissements d'enseignement et de recherche français ou étrangers, des laboratoires publics ou privés. 
Article title: Potential Mechanisms Involved in Resistant Phenotype of MCF-7 Breast Carcinoma Cells to Ionizing Radiation-Induced Apoptosis

Authors: Yan-ling Wang ${ }^{1,2,3}$, Hong Zhang ${ }^{1,2}{ }^{*}$, Ning $\mathrm{Li}^{1,2,3}$, Xiao-hu Wang ${ }^{4}$, Ji-fang Hao ${ }^{1,2}$, Wei-ping Zhao ${ }^{1,2,3}$

\section{Affiliations:}

1 Institute of Modern Physics, Chinese Academy of Sciences, Lanzhou 730000, China;

2 Key Laboratory of Heavy Ion Radiation Medicine of Gansu Province, Lanzhou 730000, China;

3 Graduate School of Chinese Academy of Sciences, Beijing 100039, China;

4 Department of Radiotherapy, Gansu Tumor Hospital, Lanzhou 730050, China

* Corresponding author: Hong Zhang

Address: Institute of Modern Physics, Chinese Academy of Sciences, 509 Nanchang Road,

Lanzhou 730000, Gansu Province, China.

Tel: +869314969344.

Fax: +86931 8272100

E-mail address: zhangh@impcas.ac.cn 


\section{Abstract:}

In the present study, we investigated the mechanisms of apoptosis resistance and the roles of the phosphorylation of BRCA1, p21, the $\mathrm{Bax} / \mathrm{Bcl}-2$ protein ratio and cell cycle arrest in IR-induced apoptosis in MCF-7 cells. X-irradiation, in particular at low dose (1Gy), but not carbon ion irradiation, had a significant antiproliferative effect on the growth of MCF-7 cells. 1Gy X-irradiation resulted in G1 and G2 phase arrest, but 4Gy induced a significant G1 block. In contrast, carbon ion irradiation resulted in a significant accumulation in the G2 phase. Concomitant with the phosphorylation of $\mathrm{H} 2 \mathrm{AX}$ induced by DNA damage, carbon ion irradiation resulted in an approximately 2.0-2.8-fold increase in the phosphorylation of BRCA1 on serine residue 1524 , significantly greater than that detected for $\mathrm{X}$-irradiation. Carbon ion irradiation caused a dramatic increase in p21 expression and drastic decrease in Bax expression compared with X-irradiation. The data implicated that phosphorylation of BRCA1 on serine residue 1524 might, at least partially, induce p21 expression but repress Bax expression. Together, our results suggested that the phosphorylation of BRCA1 at Ser-1524 might contribute to the G2 phase arrest, and might be an upstream signal involved in preventing apoptosis signal via upregulation of p21 and downregulation of the $\mathrm{Bax} / \mathrm{Bcl}-2$ ratio.

PACS codes: 87.17.Ee; 87.18.Mp; 87.19.xj

Key words: BRCA1; phosphorylation; ionizing radiation (IR); p21; Bax; Bcl-2

\section{Introduction}

Previous studies suggested that MCF-7 cells show a sensitivity to ionizing radiation (IR) for low doses irradiations [1][2], but a resistant phenotype for high doses exposures [3]. Mechanisms causing resistance are diverse and poorly defined; however, recent evidence suggests that aberrant 
apoptosis contributes to this phenomenon. Apoptosis is a normal process by which unwanted cells in multicellular organisms are eliminated during embryonic development and in adult life [4][5]. Apoptosis also plays a major role in counteracting tumor growth and, therefore, defects in apoptotic signaling pathways are one of the hallmarks of cancer [6][7]. Apoptosis is mediated through two major pathways, the death receptor pathway and the mitochondrial pathway [8]. The mitochondrial pathway is controlled and regulated by the Bcl-2 family [9-11]. This protein family can be divided into anti-apoptotic (e.g. Bcl-2 and Bcl-xL) and pro-apoptotic (e.g. Bax and Bad) members [12-14]. Loss of Bax and overexpression of Bcl-2 had all been implicated in resistance mechanisms. While the apoptotic pathways are now reasonably well understood, the upstream signal effectors in regulating mitochondrial apoptosis signaling following DNA damage is less well defined. An accumulating body of evidence has implicated that BRCA1 might be a good candidate.

BRCA1 is a breast and ovarian specific tumor suppressor and plays an important role in preserving genomic integrity. It has been demonstrated that BRCA1 plays a central role in promoting accurate repair of DNA double-strand breaks (DSBs) by both homologous recombination (HR) and non-homologous end joining (NHEJ) [15-23]. Moreover, data suggest that mutation of BRCA1 result in a radiosensitive phenotype, probably owing to a dysfunction in DSBs repair [24][25]. BRCA1 may also play a role in controlling gene transcription. BRCA1 has been found to interact with a number of transcription factors, such as p53 [26-28]. However, it appears that BRCA1 can activate transcription in some cases and repress transcription in some others [26-29]. Furthermore, many studies have implied that phosphorylation of BRCA1 is an important means by which its cellular functions are regulated. It was found that 
ataxia-telangiectasia-mutated protein (ATM) can bind and phosphorylate BRCA1 directly in response to DNA damage [30][31]. The ATM gene plays a critical role in DSBs repair and mutations in ATM result in profound cellular radiosensitivity [32]. Both ATM and BRCA1 have been shown to be present in a large complex of repair proteins that may have a role in the sensing and processing of DNA damage [33].

Serine 1524 in BRCA1, a major phosphorylation site by ATM, is associated with the regulation of cell growth after IR [34][35]. This phosphorylated form localizes to nuclear foci within $2 \mathrm{~h}$ after DNA damage, suggesting that phosphorylation might regulate the localization of BRCA1 [31]. Moreover, it has been demonstrated that prior ATM/ATR-dependent phosphorylation of BRCA1 at Ser-1524 regulated the ability of ATM/ATR to phosphorylate $\mathrm{p} 53^{\text {Ser-15 }}$ efficiently [36]. Phosphorylation of $\mathrm{p} 53^{\mathrm{Ser}-15}$ is necessary for an IR-induced G1 arrest via transcriptional induction of the cyclin-dependent kinase inhibitor p21. However, the present study reports that the G2 arrest is associated with upregulation of p21 in MCF-7 cells [37], and the radioresistant phenotype of these cells is accompanied by a persistent arrest in the G2 phase, which is be postulated that this event prevents the generation of apoptotic signal [3]. Apoptosis is mediated by the Bcl-2 family. Overexpression of $\mathrm{Bcl}-2$ in relation to Bax promotes survival, but overexpression of Bax accelerates cell death. Based on these data, it is tempting to speculate that there are interfaces between the function of BRCA1, cell cycle arrest and apoptosis signaling. In the present study, we examined the antiproliferative effect of exposure to X rays or carbon ions on the growth of MCF-7 cells, and investigated the mechanisms of apoptosis resistance and the roles of the phosphorylation of BRCA1 on serine residue 1524, $\mathrm{p} 21$, the $\mathrm{Bax} / \mathrm{Bcl}-2$ protein ratio, and cell cycle arrest in IR-induced apoptosis. 


\section{Materials and methods}

\subsection{Cell culture and irradiation}

The human breast cancer cell line MCF-7 was obtained from the American Type Culture Collection and was maintained in Dulbecco's Modified Eagle's Medium (DMEM; Gibco) with $10 \%$ fetal bovine serum in $5 \% \mathrm{CO}_{2}$ at $37^{\circ} \mathrm{C}$.

$X$-irradiation. Cells in exponential growth were irradiated with 1.0 and 4.0Gy using the X-ray therapy unit (Gansu Tumor Hospital, Lanzhou) at a dose rate of 1.0Gy/min.

Carbon ion irradiation. Cells in exponential growth were irradiated using carbon ion beams with $33.7 \mathrm{MeV} / \mathrm{u}$ energy and $61.1 \mathrm{keV} / \mu \mathrm{m}$ LET in the water generated from the irradiation equipment at the Heavy Ion Research Facility (HIRFL, Institute of Modern Physics, Chinese Academy of Sciences, Lanzhou, China) at a dose rate of $1 \mathrm{~Gy} / \mathrm{min}$. The single doses of radiation were 1.0 and $4.0 \mathrm{~Gy}$, respectively. The collimation of the beam to the place irradiation was controlled by a microcomputer. The acquisition of data (preset numbers converted by doses of irradiation) was automatically accomplished using a microcomputer during irradiation. Particle fluence was determined from an air-ionization chamber signal according to the calibration of the detector (PTW-UNIDOS, PTW-FREIBURG Co., Germany). Unirradiated cells were sham-treated.

\subsection{In vitro cell proliferation analysis}

The rate of cellular proliferation was analyzed with a real-time cell electronic sensing (RT-CES) system (ACEA Bioscience, San Diego, CA) [38]. Cells were grown on the surfaces of microelectronic sensors, which are composed of a circle-on-line electrode arrays and are integrated into the bottom surfaces of the microtiter plate. Changes in cell number were monitored 
and quantified by detecting sensor electrical impedance. Cell index (CI) values obtained on the RT-CES system were quantitatively correlated with the cell numbers. The cells were harvested after irradiation and seeded into a 16-well strip at a density of $1 \times 10^{3}$ cells/well for carbon ion irradiation and $2 \times 10^{3}$ cells/well for X-irradiation. The sensor devices were placed into the $5 \% \mathrm{CO}_{2}$ incubator, and the cell index value was determined every 15 minutes automatically by the RT-CES system for up to $36 \mathrm{~h}$.

\subsection{Cell cycle distribution analysis}

Following incubation, the cells were trypsinized, washed twice with cold phosphate buffered solution (PBS), fixed with 70\% ethanol in PBS for $30 \mathrm{~min}$, and then stained with a solution containing $5 \mu \mathrm{g} / \mathrm{ml}$ propidium iodide (PI), $10 \mathrm{kU} / \mathrm{ml}$ RNase (Sigma), and $0.005 \%$ Triton- 100 in the dark for $30 \mathrm{~min}$ at room temperature before flow cytometric analysis. The samples were detected with FACSCalibur (Becton, Dickinson and Company, USA). A minimum of 10000 cells analyzed in each sample served to determine the percentages of cells in each phase of the cell cycle using Flowjo 7.2.1 software. Three independent experiments were performed.

\subsection{Western blot analysis}

At 1, 4, 12, 24 and 36h post-irradiation, cells were washed twice with cold PBS and then lysed in RIPA buffer $(50 \mathrm{mM}$ Tris- $\mathrm{HCl}, 150 \mathrm{mM} \mathrm{NaCl}, 1.0 \%$ Nonidet P-40, 0.5\% sodium deoxycholate, $0.05 \%$ sodium dodecyl sulfate). Protein concentrations were determined with the BCA assay (Thermo Scientific). $20 \mu \mathrm{g}$ of total cellular protein from the samples were boiled for $5 \mathrm{~min}$, subjected to $10 \%$ or $15 \%$ SDS-PAGE, and transferred to a Hybond membrane (Amersham). The membrane was blocked in TBS containing 3\% BSA and $0.1 \%$ Tween 20 and probed with a primary antibody and secondary antibody. Primary antibodies used were rabbit polyclonal 
antibody to BRCA1 phospho-Ser1524, H2AX phospho-Ser139 (Cell Signaling Technology, Inc.); p21, Bax, Bcl-2 and $\beta$-actin (Santa Cruz Biotechnology, Inc.). Secondary antibody is horseradish peroxidase-conjugated goat anti-rabbit IgG (Millipore Corporation). Secondary probes were detected by ECL Western blot detection reagents and analysis system (Amersham). The expression of protein was quantified by densitometric analysis using AlphaEaseFC software (Alpha Innotech Corporation).

\subsection{Statistical analysis}

The means of three independent experiments (triplicate samples) \pm SD are shown, and statistical calculation was done using Microsoft Excel. For statistical significance, Student's t-test values were calculated. $\mathrm{P}<0.05$ was considered to be statistically significant.

\section{Results}

\subsection{Effects of exposure to $\mathrm{X}$ rays or carbon ions on cell growth}

The cell proliferation after irradiation was dynamically monitored by RT-CES system (Fig.1). As shown in Fig.1. A, exposure MCF-7 cells to $1 \mathrm{~Gy} X$ rays resulted in a significant time-dependent decrease of cell viability compared with non-irradiated cells. Similar results were obtained with 4Gy X rays irradiation, but the rate of this decrease was slower than that of $1 \mathrm{~Gy} X$ rays. Moreover, this cell growth inhibition was observed at $1 \mathrm{~h}$ post-irradiation for $1 \mathrm{~Gy}$, but at $8 \mathrm{~h}$ post-irradiation for $4 \mathrm{~Gy}$.

In contrast, we observed a dramatic difference in cell viability when cells were exposed to carbon ions (Fig.1. B). The rate of cellular proliferation was enhanced after carbon ion irradiation with $1 \mathrm{~Gy}$ and $4 \mathrm{~Gy}$, at least for $36 \mathrm{~h}$ of exposure. Together, these data suggest that MCF-7 cells show a sensitivity to cell death for low doses irradiations, but a resistant phenotype for high doses 
exposures.

\subsection{Effects of $\mathrm{X}$ rays or carbon ions on cell cycle distribution}

Cell cycle distribution was assessed by flow cytometry. As shown in Fig.2, cells showed accumulation in the $\mathrm{G} 1$ phase after $1 \mathrm{~Gy} \mathrm{X}$-irradiation. At $12 \mathrm{~h}$ post-irradiation, the percentage of cells in the G1 phase was $33.94 \%$, significantly greater than that for untreated control cells $(\mathrm{p}<0.018)$, and this significant G1 block remained until 36h $(\mathrm{p}<0.022)$. Moreover, G2/M population also significantly increased after 1Gy exposure compared with non-irradiated cells $(\mathrm{p}<0.035)$. Similar G1 phase arrest was observed for $4 \mathrm{~Gy} \mathrm{X}$-irradiation. In addition, significant accumulation of cells in the G2/M phase was detected at $12 \mathrm{~h}$ after $4 \mathrm{~Gy}$ exposure $(\mathrm{p}<0.003)$, which was followed by the population decline at $24 \mathrm{~h}$. At this point, the percentage of cells in G1 phase was significantly increased $(\mathrm{p}<0.001)$. This was because cells passed through the $\mathrm{G} 2 / \mathrm{M}$ checkpoint and finally accumulated in the G1 phase at $24 \mathrm{~h}$. Our results also showed that the sub-G1 population of apoptotic cells significantly increased following X-irradiation, but the apoptosis by $1 \mathrm{~Gy}$ is significantly more than that by $4 \mathrm{~Gy} \mathrm{X}$ rays $(\mathrm{p}<0.05)$.

In contrast, MCF-7 cells were only found to accumulate in the G2/M phase after carbon ion irradiation. At $1 \mathrm{~h}$ post-irradiation, the percentage of cells in the $\mathrm{G} 2 / \mathrm{M}$ phase was $30.49 \%$ for $1 \mathrm{~Gy}$ and $30.41 \%$ for $4 \mathrm{~Gy}$, significantly greater than that detected for untreated cells $(\mathrm{p}<0.008$ and $\mathrm{p}<0.008$, respectively). At $12 \mathrm{~h}$ after $4 \mathrm{~Gy}$ exposure, the number of cells in $\mathrm{G} 2 / \mathrm{M}$ phase reached a maximum at $36.7 \%$ and was about $20 \%$ greater compared with non-irradiated cells $(\mathrm{p}<0.001)$. Although the levels had to some extent decreased within 36h after 1Gy and 4Gy exposure, the $\mathrm{G} 2 / \mathrm{M}$ population was still significantly greater than that for untreated cells $(\mathrm{p}<0.003$ and $\mathrm{p}<0.001$, respectively). In addition, carbon ion irradiation resulted in a slight increase in the sub-G1 
population of apoptotic cells compared with untreated cells.

\subsection{DNA damage repair and apoptosis related proteins expressions after exposure to $\mathrm{X}$ rays} or carbon ions

\subsubsection{Effects of $\mathrm{X}$ rays or carbon ions on the phosphorylation of H2AX on serine residue 139}

The initial event following exposure to IR is the generation of DSBs. One of the first steps in the cellular response to DSBs is phosphorylation of histone H2AX at serine 139 [39]. To investigate the extent of DSBs induced by $\mathrm{X}$ rays or carbon ion irradiation, we examined the phosphorylation of H2AX by Western blotting. As shown in Fig.3 and Table 1, at $1 \mathrm{~h}$ post-irradiation, phosphorylated $\mathrm{H} 2 \mathrm{AX}$ (also called $\gamma$-H2AX) increased approximately 1.3 -fold for 1Gy, but about 1.5 -fold for $4 \mathrm{~Gy} \mathrm{X}$-irradiation. The same results were observed after carbon ion irradiation. The levels of $\gamma$ - $\mathrm{H} 2 \mathrm{AX}$ increased an approximately 1.6-fold for1Gy and 1.7-fold for 4Gy. In addition, the strong band representing $\gamma$-H2AX protein was still detectable at $4 \mathrm{~h}$ after carbon ion irradiation; otherwise, X-irradiation only induced the expression of $\gamma$ - $\mathrm{H} 2 \mathrm{AX}$ at $1 \mathrm{~h}$ post-irradiation. These results suggested that carbon ion irradiation resulted in more serious and lasting DSBs compared with X-irradiation.

\subsubsection{Effects of $\mathrm{X}$ rays or carbon ions on the phosphorylation of BRCA1 on serine residue} 1524

BRCA1 plays a central role in promoting accurate DSBs repair and serine 1524 in Brcal is a major phosphorylation site by ATM. Thus, we examined the phosphorylation of BRCA1 at Ser-1524 by Western blotting (Fig. 3 and Table 1). The phosphorylation of BRCA1 was not significantly affected by 1 Gy X-irradiation, but remarkably enhanced by 4Gy X-irradiation and revealed an approximately 1.6-2.5-fold increase. In contrast, carbon ion irradiation induced a 
drastic increase in the phosphorylation of BRCA1 and showed approximately 2.1-2.8-fold for 1Gy and 1.9-2.8-fold for 4Gy increase compared with untreated cells. These data showed that the dramatic increase of phosphorylation of BRCA1 on serine residue 1524 was corresponding with the drastic increase of phosphorylation of histone $\mathrm{H} 2 \mathrm{AX}$, which suggested the phosphorylation of BRCA1 on serine residues 1524 played a role in the signaling of DNA damage and DNA repair.

\subsubsection{Effects of $\mathrm{X}$ rays or carbon ions on p21 expression and the radio of Bax/Bcl-2}

The present study reports that the G2 arrest is associated with upregulation of p21 in MCF-7 cells [37]. It has been suggested that a persistent arrest in the G2 phase prevents the generation of apoptotic signal [3]. The Bcl-2 family has been identified as an important regulator of mammalian cell death with both anti-apoptotic (e.g. Bcl-2 and Bcl-xL) and pro-apoptotic (e.g. Bax and Bad) members. We analyzed for expression of $\mathrm{p} 21$, Bax and Bcl-2 proteins by Western blotting.

As shown in Fig. 3 and Table 1, the expression of p21 was not significantly affected by 1 Gy $\mathrm{X}$-irradiation, but remarkably induced by 4Gy X-irradiation and revealed an approximately 1.2-3.0-fold increase. Carbon ion irradiation induced a drastic increase in p21 expression and showed approximately 3.3-8.0-fold for 1Gy and 5.8-8.6-fold for 4Gy increase compared with untreated cells. A significantly increased band representing Bax protein was seen in MCF-7 cells after 1Gy X-irradiation and showed an approximately 1.3-2.0-fold increase, but decreased approximately 1.3-2.4-fold when 4Gy X-irradiation. The expression of Bcl-2 protein was slightly decreased after $\mathrm{X}$-irradiation. However, carbon ion irradiation resulted in a dramatic decrease in the expression of Bax protein and showed about 1.1-2.4-fold for 1Gy and 1.5-4.6-fold for 4Gy decline. In the case of Bcl-2 protein, carbon ions had no significant effect on its expression.

\section{Discussion}


In this paper, we observed that carbon ion irradiation had no inhibition effect on the growth of MCF-7 cells. In contrast, X-irradiation, in particular, low dose irradiation (1Gy) had a significant antiproliferative effect on the growth of cells. The radiation-resistant phenotype of MCF-7 cells had been reported, for example, MCF-7 cells were radioresistant to 20Gy gamma rays [3]. Other studies demonstrated that low doses of IR enhanced the cellular sensitivity to apoptosis [1][2]. Similarly, our data also showed that low dose X-irradiation resulted in a significant growth inhibition. Dysfunction of apoptotic pathways has been implicated in the development of resistance to IR. In this line, we investigated the key components of the apoptosis signaling transduction machinery, namely, the Bcl-2 family members and analyzed the sub-G1 population of apoptotic cells following IR. The ratio of Bax to Bcl-2 regulates the susceptibility to apoptosis, whereby overexpression of Bcl-2 in relation to Bax promotes survival, but overexpression of Bax accelerates cell death [40][41]. Our data showed that $1 \mathrm{~Gy}$ X-irradiation resulted in an approximately 1.3-2.0-fold increase in Bax expression, but had no significant effect on Bcl-2 expression, leading to an increase of the Bax/Bcl-2 ratio, as reported previously [42]. For 4Gy $\mathrm{X}$-irradiation, the expression of Bax reduced and the Bax/Bcl-2 radio decreased. Accordingly, the cell apoptosis induced by $1 \mathrm{~Gy}$ is significantly more than that by $4 \mathrm{~Gy} \mathrm{X}$ rays (Fig.2). In contrast, exposure of cells to carbon ions resulted in a dramatic decrease of the Bax expression leading to a decrease of the $\mathrm{Bax} / \mathrm{Bcl}-2$ ratio and a slight increase in the sub-G1 population of apoptotic cells compared with untreated cells. These data suggest that the dysfunction of apoptosis contributes to cellular resistance to IR.

In addition to apoptosis, DNA damage by IR triggers the cell cycle checkpoint control signaling, and the subsequent cell cycle arrest, augmenting the ability of cells to repair damaged 
DNA. Our data showed that 1Gy X-irradiation resulted in G1 and G2 phase arrest, as reported previously [43], but 4Gy X-irradiation induced a significant G1 block. In contrast, carbon ion irradiation resulted in a significant accumulation in the G2 phase. This finding was in agreement with the previous study that the radioresistant phenotype of MCF-7 cells was accompanied by an arrest in the G2 phase [3]. It is be postulated that this event prevents the generation of apoptotic signal. Several reports showed that the abrogation of the G2 checkpoint by caffeine resulted in a marked increase in the sensitivity of various tumor cells to IR and certain chemotherapeutic agents [44][45]. Although it probably targets several proteins, the release of the G2 block by caffeine is most likely mediated by inhibition of the ATM/ATR kinases [46].

BRCA1 is an ATM target and phosphorylated by ATM on multiple serine residues in response to DNA damage [30][31]. An accumulating body of evidence has implicated that BRCA1 may play a role in controlling gene transcription. BRCA1 has been found to interact with a number of transcription factors, such as p53 [26-28] and c-Myc [47]. In these studies, however, it appears that BRCA1 can activate transcription in some cases and repress transcription in some others. For example, BRCA1 can bind to p53 and enhance its transcription activity at the promoter of p21 [26][27][29], but in some cases repressed Bax expression[28]. Many studies have implied that phosphorylation of BRCA1 is an important means by which its cellular functions are regulated. It is not clear how the functions of BRCA1 are modulated by phosphorylation. Perhaps, the phosphorylation states of BRCA1 determine its ability to bind to other proteins and affect its biochemical activities in DNA damage repair or gene transcription [48], or may affect its cellular localization or stability. Serine 1524 in BRCA1, a major phosphorylation site by ATM, is associated with the regulation of cell growth after IR and may regulate the localization of BRCA1. 
Moreover, it has been demonstrated that prior ATM/ATR-dependent phosphorylation of BRCA1 at Ser-1524 regulated the ability of ATM/ATR to phosphorylate $553^{\text {Ser-15 }}$ efficiently [36], while the later is necessary for transcriptional induction of $\mathrm{p} 21$. The present study reports that the G2 arrest is associated with the upregulation of p21 in MCF-7 cells [37], and a previous study demonstrated the apoptosis sensitizing effect of p21 inactivation [49]. Therefore, we hypothesized that phosphorylation of BRCA1 on serine residue 1524 might contribute to the G2 phase arrest and might be an upstream signaling involved in preventing apoptosis signaling following DNA damage. Our data showed that $1 \mathrm{~Gy} \mathrm{X}$-irradiation had no significant effect on the phosphorylation of BRCA1 on serine residue 1524 and p21 expression, but induced a significant increase in the Bax expression leading to enhance Bax/Bcl-2 radio in MCF-7 cells. For 4Gy X-irradiation, the levels of BRCA1 phosphorylation increased about 1.6-2.5-fold and p21 levels increased about 1.2-3.0-fold, but the Bax expression decreased about 1.3-2.4-fold. Carbon ion irradiation induced a drastic increase in expression of the phosphorylation of BRCA1, accordingly, p21 expression enhanced and Bax expression decreased remarkably. These data showed that the phosphorylation of BRCA1 on serine residue 1524 might, at least partially, induce p21 expression but repress Bax expression.

Based on our and previous results, we propose ATM phosphorylates H2AX in response to DNA damage, which forms $\gamma$-H2AX foci at the sites of DSBs. At these sites, $\gamma$ - $\mathrm{H} 2 \mathrm{AX}$ then recruits DNA repair and damage-response proteins [50], including BRCA1. ATM then activates and phosphorylates BRCA1, which may transmit a signal from sensors of DNA damage to a 'switch' that determines cell cycle arrest versus apoptosis.

In summary, we have shown that the resistant phenotype of MCF-7 cells toward IR-induced 
apoptosis is modulated by the Bax/Bcl-2 ratio. The phosphorylation of BRCA1 on serine residue 1524, at least partially, might contribute to the G2 phase arrest and might be an upstream signaling involved in preventing apoptosis signaling following DNA damage via upregulation of p21 and downregulation of the $\mathrm{Bax} / \mathrm{Bcl}-2$ ratio.

\section{Acknowledgements}

The authors would like to thank the operating crew of the HIRFL accelerator for supplying the carbon beam, and the accelerator crew at Department of Radiotherapy, Gansu Tumor Hospital in Lanzhou, for supplying X-ray. This work was supported by grants from the National Natural Science Foundation of China $(10675151,10805064)$, the Key Scientific Technology Research Projects of Gansu Province (O702NKDA045), the Scientific Technology Research Project of Lanzhou-Chinese Academy of Sciences (07-2-07) and Western Talent Program of Chinese Academy of Sciences (0860260XBO, 0760160XBO).

\section{References}

[1] J. Soto, C. Sainz, D. González-Lamuño and S. Cos, Oncol. Rep. 5 (2006) 577.

[2] J. Soto, C. Sainz, D. Gonzalez-Lamuno, A. Falkenbach and S. Cos, Oncol. Rep. 7 (2000) 941.

[3] R.U. Jänicke, I.H. Engels, T. Dunkern, B. Kaina, K. Schulze-Osthoff and A.G. Porter, Oncogene. 20 (2001) 5043.

[4] N.N. Danial and S.J. Korsmeyer, Cell. 116 (2004) 205.

[5]A. Strasser, L. O'Connor and V.M. Dixit, Annu. Rev. Biochem. 69 (2000) 217.

[6] D. Hanahan and R.A. Weinberg, Cell. 100 (2000) 57.

[7] M. Jäättelä, Oncogene. 23 (2004) 2746.

[8] M.O. Hengartner, Nature. 407(2000)770. 
[9] E. Yang and S.J. Korsmeyer, Blood. 88(1996)386.

[10] D.R. Green and J.C. Reed, Science. 281(1998)1309.

[11] A. Kelekar and C.B. Thompson, Trends Cell Biol. 8(1998)324

[12] G. Kroemer, Nat. Med. 3(1997)614.

[13] M.D. Jacobson, Curr Biol. 7(1997)R277.

[14] J.C. Reed, Nature. 387(1997)773.

[15] J. Yun, Q. Zhong, J.Y. Kwak and W.H. Lee, Oncogene. 24 (2005) 4009.

[16] R. Scully, A. Xie and G. Nagaraju, Cancer Biol. Ther. 3 (2004) 521.

[17] S.N. Powell and L.A. Kachnic, Oncogene. 22 (2003) 5784.

[18] D.T. Bau, Y.P. Fu, S.T. Chen, T.C. Cheng, J.C. Yu, P.E. Wu and C.Y. Shen, Cancer Res. 64 (2004) 5013.

[19] Q. Zhong, T.G. Boyer, P.L. Chen and W.H. Lee, Cancer Res. 62 (2002) 3966.

[20] H. Wang, Z.C. Zeng, T.A. Bui, S.J. DiBiase, W. Qin, F. Xia, S.N. Powell and G. Iliakis, Cancer Res. 61 (2001) 270.

[21] R. Scully, J. Chen, A. Plug, Y. Xiao, D. Weaver, J. Feunteun, T. Ashley and D.M. Livingston, Cell. 88 (1997) 265.

[22] K. Yamane, E. Katayama and T. Tsuruo, Biochem. Biophys. Res. Commun. 279 (2000) 678.

[23] T.T. Paull, D. Cortez, B. Bowers, S.J. Elledge and M. Gellert, Proc. Natl. Acad. Sci. U. S. A. $98(2001) 6086$.

[24] L.C. Gowen, A.V. Avrutskaya, A.M. Latour, B.H. Koller and S.A. Leadon, Science. 281 (1998) 1009.

[25] Q. Zhong, C.F. Chen, S. Li, Y. Chen, C.C. Wang, J. Xiao, P.L. Chen, Z.D. Sharp and W.H. 
Lee, Science.285 (1999) 747.

[26] T. Ouchi, A.N. Monteiro, A. August, S.A. Aaronson and H. Hanafusa, Proc. Natl. Acad. Sci. U. S. A. 95 (1998) 2302.

[27] H. Zhang, K. Somasundaram, Y. Peng, H. Tian, H. Zhang, D. Bi, B.L. Weber and W.S. El-Deiry, Oncogene. 16 (1998) 1713.

[28] T.K. MacLachlan, K. Somasundaram, M. Sgagias, Y. Shifman, R.J. Muschel, K.H. Cowan and W.S. El-Deiry, J. Biol. Chem. 275 (2000) 2777.

[29] T.K. MacLachlan, R. Takimoto and W.S. El-Deiry, Mol. Cell Biol. 22 (2002) 4280.

[30] M. Gatei, S.P. Scott, I. Filippovitch, N. Soronika, M.F. Lavin, B. Weber and K.K. Khanna, Cancer Res. 60 (2000) 3299.

[31] M. Gatei, B.B. Zhou, K. Hobson, S. Scott, D. Young and K.K. Khanna, J. Biol. Chem. 276 (2001) 17276.

[32] D. Blöcher, D. Sigut and M.A. Hannan, Int. J. Radiat. Biol. 60 (1991) 791.

[33] Y. Wang, D. Cortez, P. Yazdi, N. Neff, S.J. Elledge and J. Qin, BASC, Genes Dev. 14 (2000) 927.

[34] D, Cortez, Y, Wang, J, Qin and S.J. Elledge, Science. 286 (1999) 1162.

[35] R. Scully, S. Ganesan, K. Vlasakova, J. Chen, M. Socolovsky and D.M. Livingston, Mol, Cell. 4 (1999) 1093.

[36] M. Fabbro, K. Savage, K. Hobson, A.J. Deans, S.N. Powell, G.A. McArthur and K.K. Khanna, J. Biol. Chem. 279 (2004) 31251.

[37] J. Wendt, S. Radetzki, C. von Haefen, P.G. Hemmati, D. Güner, K. Schulze-Osthoff, B. Dörken and P.T. Daniel, Oncogene. 25 (2006) 972. 
[38] K. Solly, X. Wang, X. Xu, B. Strulovici and W. Zheng, Assay Drug. Dev. Technol. 2 (2004) 363.

[39] E.P. Rogakou, D.R. Pilch, A.H. Orr, V.S. Ivanova and W.M. Bonner, J. Biol. Chem. 273 ( 1998) 5858.

[40] T.W. Sedlak, Z.N. Oltvai, E. Yang, K. Wang, L.H. Boise, C.B. Thompson and S.J. Korsmeyer, Proc. Natl. Acad. Sci. U. S. A. 92 (1995) 7834.

[41] Z.N. Oltvai, C.L. Milliman and S.J. Korsmeyer, Cell. 74 (1993) 609.

[42] S. Kitada, S. Krajewski, T. Miyashita, M. Krajewska and J.C. Reed, Oncogene. 12 (1996) 187.

[43] S. Fan, M.L. Smith, D.J. Rivet 2nd, D. Duba, Q. Zhan, K.W. Kohn, A.J. Fornace Jr and P.M. O'Connor, Cancer Res. 55 (1995) 1649.

[44] P.K. Narayanan, J.M. Rudnick, E.A. Walthers and H.A. Crissman, Exp. Cell Res. 233 (1997) 118.

[45] M. Bache, S. Pigorsch, J. Dunst, P. Würl, A. Meye, F. Bartel, H. Schmidt, F.W. Rath and H .Taubert, Int. J. Cancer. 96 (2001) 110.

[46] J.N. Sarkaria, E.C. Busby, R.S. Tibbetts, P. Roos, Y. Taya, L.M. Karnitz and R.T. Abraham, Cancer Res. 59 (1999) 4375.

[47] Q. Wang, H. Zhang, K. Kajino and M.I. Greene, Oncogene. 17 (1998) 1939.

[48] T.K. MacLachlan, R. Takimoto and W.S. El-Deiry, Mol. Cell Biol. 22 (2002) 4280.

[49] D. Javelaud and F. Besancon, J. Biol. Chem. 277 (2002) 37949.

[50] T.T. Paull, E.P. Rogakou, V. Yamazaki, C.U. Kirchgessner, M. Gellert and W.M. Bonner, Curr. Biol. 10 (2000) 886. 


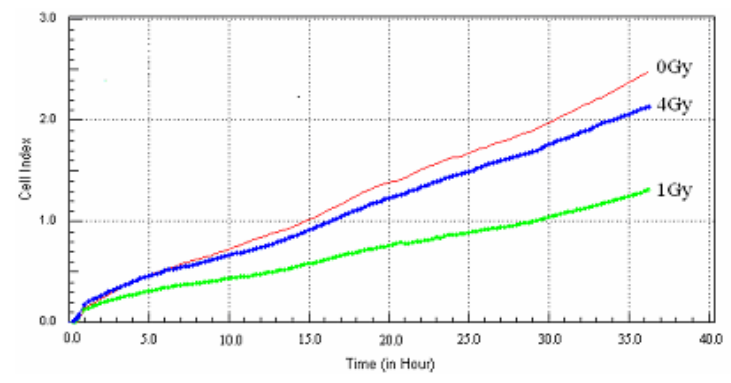

A

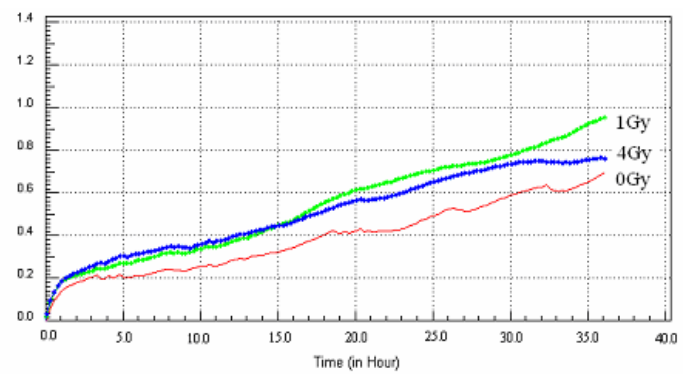

B

Fig.1. Cells were harvested after irradiation with $\mathrm{X}$ rays (A) and carbon ions (B), and the cells were seeded into a 16-well strip. Cell index values were determined every 15 minute automatically by the RT-CES system for up to $36 \mathrm{~h}$. 


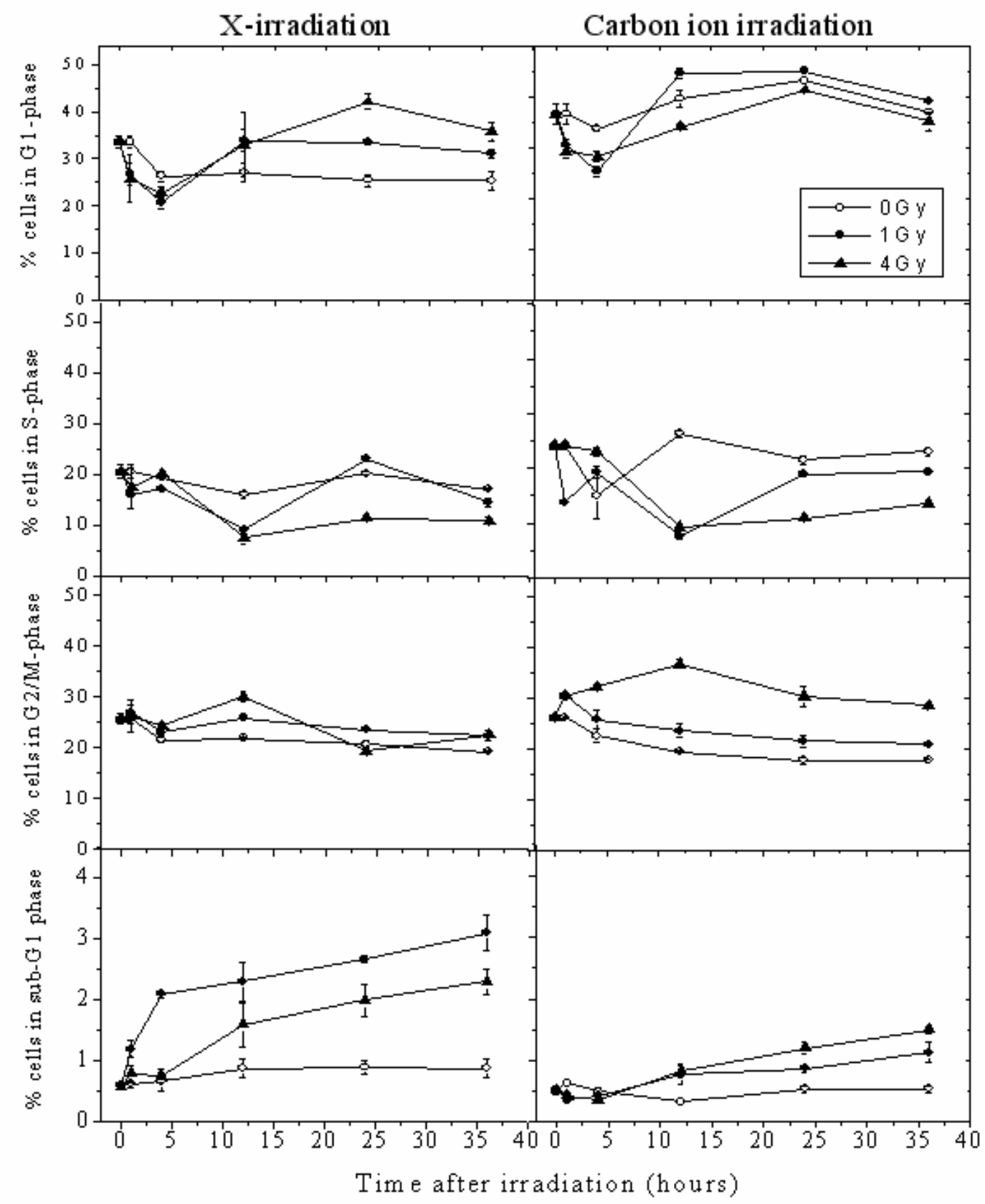

Fig.2. Cell cycle distribution in MCF-7 cells after X rays and carbon ion irraidation. Cell-cycle distribution was examined by flow cytometry. Error bars indicate the standard error of three independent experiments. 


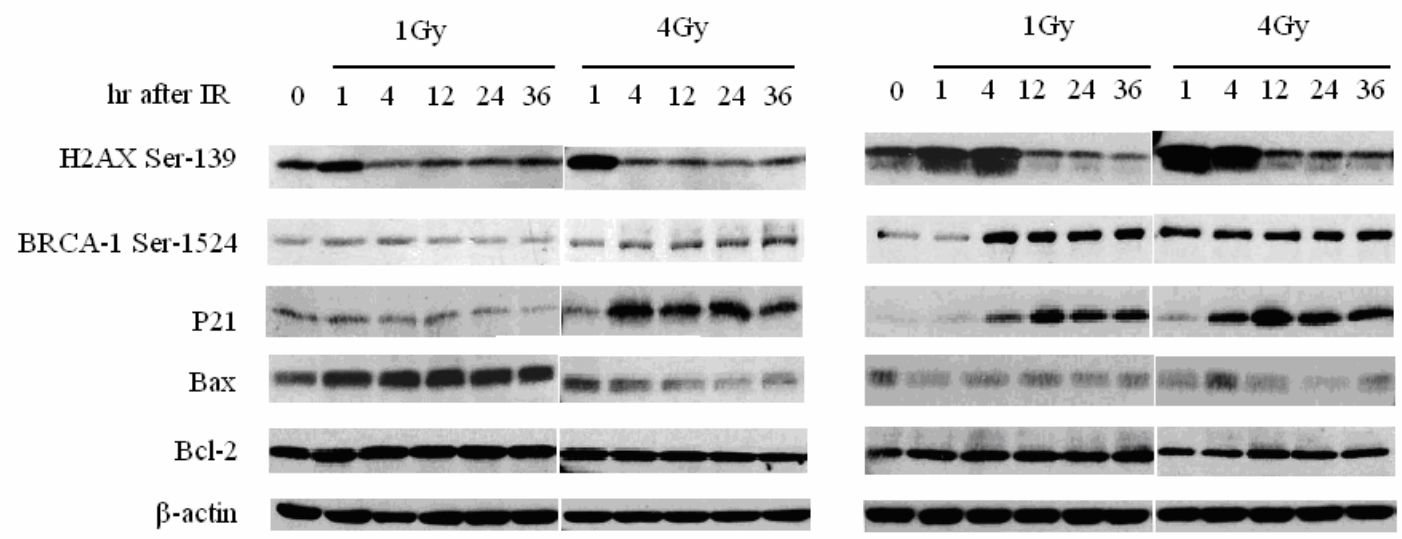

Fig.3 Effect of $\mathrm{X}$ rays and carbon ions on the expression of phosphorylation of $\mathrm{H} 2 \mathrm{AX}$ on serine residue 139 , phosphorylation of BRCA1 on serine residue $1524, \mathrm{P} 21$, Bax and Bcl-2. Equal amounts of whole cell extracts were separated on SDS-PAGE gels, and protein were detected by Western blot analysis. $\beta$-actin was used as a control.

Table 1. Levels of proteins in MCF-7 cells at different times after irradiation with X rays and carbon ions. Protein bands (Fig.3) were quantitated by densitometry and expressed as a radio of the respective $\beta$-actin levels.

\begin{tabular}{|c|c|c|c|c|c|c|c|c|c|c|c|}
\hline & \multirow[b]{2}{*}{$0 \mathrm{~h}$} & \multicolumn{5}{|c|}{$1 \mathrm{~Gy} \mathrm{X}$ rays } & \multicolumn{5}{|c|}{ 4Gy X rays } \\
\hline & & $1 \mathrm{~h}$ & $4 \mathrm{~h}$ & $12 \mathrm{~h}$ & $24 \mathrm{~h}$ & $36 \mathrm{~h}$ & $1 \mathrm{~h}$ & $4 \mathrm{~h}$ & $12 \mathrm{~h}$ & $24 \mathrm{~h}$ & $36 \mathrm{~h}$ \\
\hline$\gamma$-H2AX & $0.74 \pm 0.12$ & $0.96 \pm 0.07$ & $0.48 \pm 0.13$ & $0.57 \pm 0.10$ & $0.53 \pm 0.08$ & $0.41 \pm 0.08$ & $1.13 \pm 0.58$ & $0.60 \pm 0.08$ & $0.68 \pm 0.07$ & $0.57 \pm 0.05$ & $0.40 \pm 0.06$ \\
\hline BRCA-1 ser-1524 & $0.29 \pm 0.05$ & $0.37 \pm 0.12$ & $0.41 \pm 0.16$ & $0.30 \pm 0.05$ & $0.28 \pm 0.05$ & $0.25 \pm 0.08$ & $0.47 \pm 0.14$ & $0.60 \pm 0.10$ & $0.73 \pm 0.26$ & $0.70 \pm 0.14$ & $0.51 \pm 0.03$ \\
\hline P21 & $0.44 \pm 0.05$ & $0.40 \pm 0.08$ & $0.34 \pm 0.08$ & $0.32 \pm 0.08$ & $0.33 \pm 0.10$ & $0.39 \pm 0.07$ & $0.51 \pm 0.07$ & $1.33 \pm 0.44$ & $1.16 \pm 0.12$ & $1.25 \pm 0 . .36$ & $0.58 \pm 0.10$ \\
\hline Bax & $0.62 \pm 0.12$ & $0.85 \pm 0.22$ & $1.22 \pm 0.23$ & $0.85 \pm 0.18$ & $0.84 \pm 0.16$ & $0.80 \pm 0.07$ & $0.66 \pm 0.34$ & $0.60 \pm 0.12$ & $0.48 \pm 0.07$ & $0.32 \pm 0.03$ & $0.26 \pm 0.05$ \\
\hline \multirow[t]{3}{*}{$\mathrm{Bcl}-2$} & $0.99 \pm 0.36$ & $0.88 \pm 0.22$ & $1.05 \pm 0.26$ & $0.93 \pm 0.11$ & $0.84 \pm 0.26$ & $0.81 \pm 0.22$ & $1.00 \pm 0.42$ & $0.93 \pm 0.0 .33$ & $0.96 \pm 0.12$ & $0.84 \pm 0.23$ & $0.85 \pm 0.12$ \\
\hline & & \multicolumn{5}{|c|}{1 Gy carbon ions } & \multicolumn{5}{|c|}{ 4Gy carbon ions } \\
\hline & $0 \mathrm{~h}$ & $1 \mathrm{~h}$ & $4 \mathrm{~h}$ & $12 \mathrm{~h}$ & $24 \mathrm{~h}$ & $36 \mathrm{~h}$ & $1 \mathrm{~h}$ & $4 \mathrm{~h}$ & $12 \mathrm{~h}$ & $24 \mathrm{~h}$ & $36 \mathrm{~h}$ \\
\hline$\gamma-\mathrm{H} 2 \mathrm{AX}$ & $0.70 \pm 0.21$ & $1.00 \pm 0.14$ & $1.14 \pm 0.12$ & $0.49 \pm 0.12$ & $0.41 \pm 0.09$ & $0.43 \pm 0.22$ & $1.12 \pm 0.25$ & $1.18 \pm 0.36$ & $0.65 \pm 0.09$ & $0.62 \pm 0.10$ & $0.65 \pm 0.22$ \\
\hline BRCA-1 ser-1524 & $0.31 \pm 0.07$ & $0.30 \pm 0.05$ & $0.86 \pm 0.23$ & $0.71 \pm 0.12$ & $0.65 \pm 0.36$ & $0.65 \pm 0.22$ & $0.86 \pm 0.17$ & $0.71 \pm 0.38$ & $0.63 \pm 0.25$ & $0.60 \pm 0.12$ & $0.73 \pm 0.23$ \\
\hline P21 & $0.13 \pm 0.05$ & $0.16 \pm 0.03$ & $0.43 \pm 0.12$ & $0.86 \pm 0.22$ & $0.70 \pm 0.06$ & $1.04 \pm 0.44$ & $0.18 \pm 0.02$ & $0.75 \pm 0.22$ & $1.12 \pm 0.33$ & $0.89 \pm 0.12$ & $0.84 \pm 0.12$ \\
\hline Bax & $0.51 \pm 0.21$ & $0.27 \pm 0.02$ & $0.39 \pm 0.10$ & $0.47 \pm 0.12$ & $0.31 \pm 0.05$ & $0.38 \pm 0.10$ & $0.35 \pm 0.10$ & $0.55 \pm 0.22$ & $0.29 \pm 0.07$ & $0.11 \pm 0.02$ & $0.33 \pm 0.05$ \\
\hline Bcl-2 & $0.76 \pm 0.24$ & $0.80 \pm 0.25$ & $0.86 \pm 0.33$ & $0.90 \pm 0.12$ & $0.81 \pm 0.18$ & $0.85 \pm 0.13$ & $0.63 \pm 0.08$ & $0.69 \pm 0.12$ & $0.76 \pm 0.12$ & $0.72 \pm 0.14$ & $0.75 \pm 0.22$ \\
\hline
\end{tabular}

